\title{
Investigation on Capability of Reaming Process using Minimal Quantity Lubrication
}

\author{
De Chiffre, Leonardo; Tosello, Guido; Piska, Miroslav; Müller, Pavel
}

Published in:

Proceedings of The Swedish Production Symposium

Publication date:

2008

Link back to DTU Orbit

Citation (APA):

De Chiffre, L., Tosello, G., Piska, M., \& Müller, P. (2008). Investigation on Capability of Reaming Process using Minimal Quantity Lubrication. In B. Lindberg, \& J. Stahreand (Eds.), Proceedings of The Swedish Production Symposium: SPSO8 (pp. 85-92). Royal Institute of Technology (KTH) (Stockholm, Sweden). http://www.sps08.se

\section{General rights}

Copyright and moral rights for the publications made accessible in the public portal are retained by the authors and/or other copyright owners and it is a condition of accessing publications that users recognise and abide by the legal requirements associated with these rights.

- Users may download and print one copy of any publication from the public portal for the purpose of private study or research.

- You may not further distribute the material or use it for any profit-making activity or commercial gain

- You may freely distribute the URL identifying the publication in the public portal

If you believe that this document breaches copyright please contact us providing details, and we will remove access to the work immediately and investigate your claim. 


\title{
Investigation on Capability of Reaming Process using Minimal Quantity Lubrication
}

\author{
L. De Chiffre ${ }^{1}$, G. Tosello ${ }^{1}$, M. Píška ${ }^{2}$, P. Muller ${ }^{1,2}$ \\ ${ }^{1}$ Technical University of Denmark, \\ Department of Mechanical Engineering, Kgs. Lyngby, Denmark \\ ${ }^{2}$ Brno University of Technology, \\ Institute of Manufacturing Technology, Brno, Czech Republic \\ Idch@mek.dtu.dk
}

\begin{abstract}
An investigation on reaming using minimal quantity lubrication (MQL) was carried out with the scope of documenting process capability using a metrological approach. Reaming tests were carried out on austenitic stainless steel, using HSS reamers with different cutting data and lubrication conditions. The reaming operations were compared with respect to a number of evaluation parameters, both hole quality (diameter, roundness, cylindricity and surface roughness) and cutting forces (reaming thrust and torque). Absolute average values as well as experimental standard deviations of the evaluation parameters were calculated, and uncertainty budgeting was performed for all measurands. Results show that reaming operations at lower cutting speed and feed produce low process scatter. The use of smaller depth of cut (i.e. smaller reamer diameter) resulted in larger reaming torque scatter than when a larger depth of cut was employed. The suitability of MQL for reaming was proven under the investigated process conditions, concerning both the quality of the machined holes, in terms of geometrical characteristics and surface finishing, and the process quality, with respect to reaming torque and thrust, along with their repeatability.
\end{abstract}

\section{Keywords: Reaming, Minimal Quantity Lubrication, Measurement uncertainty}

\section{INTRODUCTION}

Cutting fluids applied in machining provide lubrication and cooling, minimizing the heat produced between the surface of the workpiece and the tool and the contact area between tool and chip [1]. However, during the last decade, a significant research has been undertaken with the aim of diminishing the quantity of cutting fluids applied in production, due to the fact that the use of large amounts of cutting fluids brings several drawbacks. Cutting fluids can be difficult and expensive to recycle, they can cause skin and lung diseases to the operator and cause air pollution. Other reasons for decreasing the quantity of cutting fluids are the costs related to the fluids, which have been evaluated to be in the range $7-17 \%$ of the overall manufacturing costs [2].

In order to minimize the use of cutting fluids and to fulfil the demands concerning health work environment, the Minimal Quantity Lubrication (MQL) technology was introduced [3]. MQL is a machining method that delivers a precise amount of lubrication to the tool tip. The lubricant is mixed with compressed air and forms the desired air/oil aerosol mixture. A classification of lubrication based on oil usage per time unit is given in Table 1.

By using MQL it is possible to achieve effective lubrication of the cutting process with extremely small quantities of oil. The result is not only higher productivity due to faster cutting speeds but also longer tool life and cost savings on cooling lubricants. By abandoning conventional cooling lubricants and taking into account only the use of this new technology, costs can be reduced significantly [3].

\begin{tabular}{|c|c|}
\hline Flow rate [ml/hour] & Lubrication type \\
\hline 0 & Dry \\
\hline$<80$ & Minimal quantity lubrication \\
\hline $80-2000$ & Minimal flow lubrication \\
\hline$>2000$ & Flood lubrication \\
\hline
\end{tabular}

Table 1 - Lubrication types in terms of flow rate.

Reaming is a common machining process with the characteristic property of enlarging, smoothing and accurately sizing existing holes to tight tolerances. The quality of the hole depends on reamer geometry, cutting conditions, application, stock removal, lubrication and the quality of the holes to be reamed. Reaming is a finishing operation which normally follows drilling or core drilling. Since stock removal is small and must be uniform in reaming, the starting holes (drilled or otherwise produced) must have relatively good roundness, straightness, and surface finish. Reamers tend to follow the existing centreline of the hole being reamed. If insufficient stock removal is left in the hole before reaming, the reamer can wear faster than normally and result in loss of diameter accuracy. In general applications, average surface roughness for reaming is expected to be in range between $0.8 \mu \mathrm{m}$ and 
$3.2 \mu \mathrm{m}$ but high-accuracy reaming can produce average surface roughness as low as $0.4 \mu \mathrm{m}$ [4].

The quality of the reaming process when using MQL was investigated. A number of different performance criteria for the manufacturing quality assessment were selected, concerning both the product and the process. In particular, the quality of the reamed holes was evaluated in terms of geometrical characteristics (diameter, roundness, cylindricity, surface roughness) while the process was evaluated by measuring cutting torque and thrust. All characteristics were considered both in terms of absolute measured values and repeatability (i.e. standard deviation). Reaming on austenitic stainless steel was considered in this work.

This work was focused on achieving a consistent documentation of the capability of the reaming operation using a metrological approach. The study is related to research at the Technical University of Denmark concerning the development of performance tests for cutting fluids, in particular those involving measurements of product quality and cutting forces [5][17]. The ultimate goal of this research is to achieve the highest resolution on a test relative to the range of variability of test results when considering different cutting fluids under the same operating conditions [7].

\section{EXPERIMENTAL SETUP FOR REAMING}

\subsection{Reaming equipment}

All the reaming tests were carried out using a CNC vertical milling centre (Cincinnati Sabre $750 \mathrm{CNC}, 7.5$ $\mathrm{KW}$ spindle power). Two reamers with $10.0 \mathrm{~mm}$ and $10.1 \mathrm{~mm}$ diameter were employed during the tests. Reamer specifications are listed in Table 2. The reamer diameter was measured before and after each test using a digital micrometer and the average value of ten measurements on three pair of flutes was calculated. This value was constant within a range of $1 \mu \mathrm{m}$ showing that no diameter reduction due to wear had occurred during the whole investigation. Reamers were clamped in a SK40x10 Röhm tool holder with a run out lower than $5 \mu \mathrm{m}$.

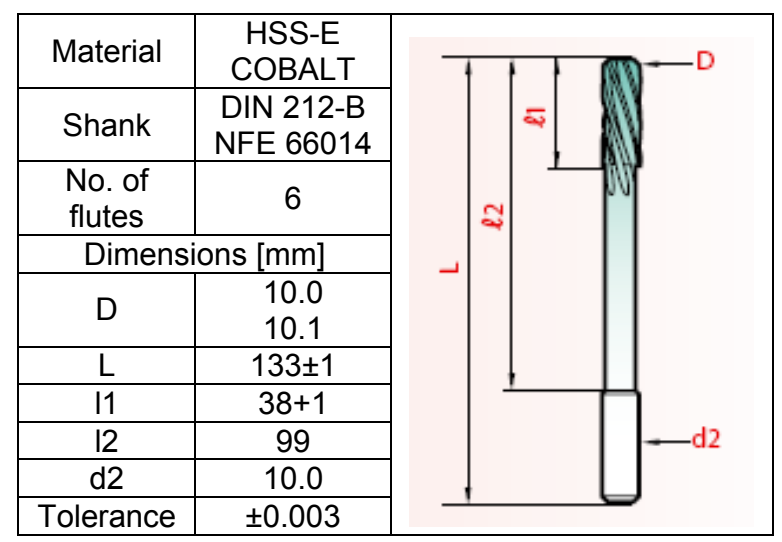

Table 2 - Reamer specifications.

\subsection{Workpiece}

The workpiece material employed in this research was austenitic steel AISI $316 \mathrm{~L}$, a low-carbon grade and non-magnetic stainless steel, Table 3.

\begin{tabular}{|c|c|c|c|}
\hline \multicolumn{2}{|c|}{ Workpiece material } & \multicolumn{2}{|c|}{ AISI 316 L Stainless stee } \\
\hline \multicolumn{2}{|c|}{ Vickers Hardness } & \multicolumn{2}{|c|}{$258.1 \mathrm{HV} 20$} \\
\hline \multicolumn{4}{|c|}{ Composition analysis } \\
\hline Element & Mass $[\%]$ & Element & Mass $[\%]$ \\
\hline $\mathrm{C}$ & 0.016 & $\mathrm{Cr}$ & 17.31 \\
\hline $\mathrm{Si}$ & 0.39 & Mo & 2.11 \\
\hline $\mathrm{Mn}$ & 1.4 & $\mathrm{~S}$ & 0.026 \\
\hline $\mathrm{P}$ & 0.027 & $\mathrm{~N}$ & 0.052 \\
\hline $\mathrm{Ni}$ & 11.21 & & \\
\hline
\end{tabular}

Table 3 - Workpiece material characteristics [8].

Such material is hard to machine due to its ductility, high strain hardening and low thermal conductivity. Chips produced are long wiry chips, and the material can easily work harden if not machined with correct feeds. The test workpieces were rings with a premanufactured hole (i.e. pilot hole). Dimension, form and surface roughness specifications of workpiece and pilot hole are listed in Table 4. Workpieces were clamped in a holder directly on a dynamometer. Tool holder and workpiece were aligned using a lever-type dial gauge.

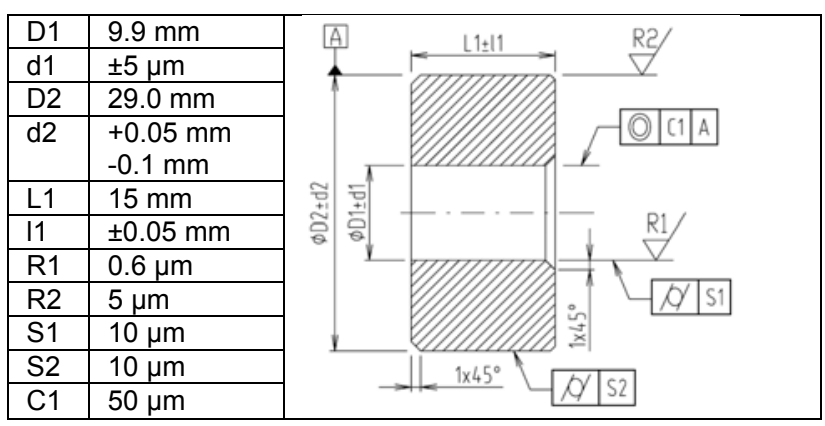

Table 4 - Workpiece specifications [8].

\section{3. $M Q L$ application}

A setup for $M Q L$ application was built up in the milling centre. Particularly for this MQL system, the oil is delivered by a Venturi-type system that pulls the oil into a pressurized air stream coming from the regulator to the fluid reservoir. The oil-air mixture is fed to the tubing and finally to the nozzles at the outlet. Two different MQL application strategies were investigated by placing the nozzles for the aerosol in two different positions: a) both nozzles delivering from the top of the workpiece being reamed (TT setup) and b) one nozzle from the top and one from the bottom, delivering the aerosol through the fixture and up to the machining area (TB setup, see Fig. 1). The oil used for the experiment was an insoluble oil with viscosity of $26 \mathrm{cSt}$ measured at $40^{\circ} \mathrm{C}$. The oil/air mixture was delivered at a pressure of 6 bar with a flow rate in the range between 50 and 60 $\mathrm{ml} /$ hour depending on the experimental conditions. 


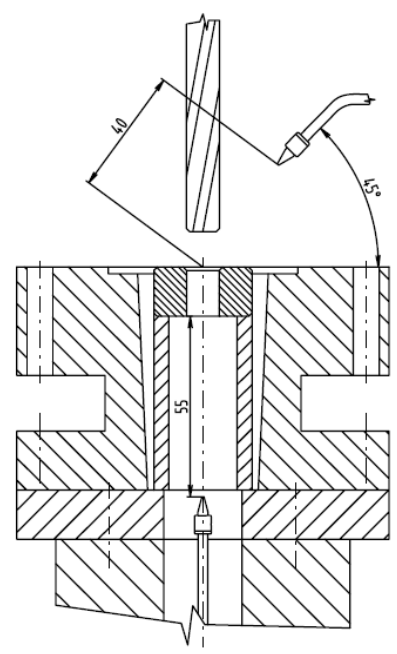

Fig. 1 - MQL application strategy TB.

\section{EXPERIMENTAL SETUP FOR MEASUREMENTS}

The capability of reaming using MQL was assessed by analyzing different output parameters under different process conditions. Parameters were measured both during the machining (reaming torque and thrust) and afterwards (hole geometry and surface topography). Measuring methods and equipment are presented in the following.

\subsection{Torque and thrust measurements}

For each reaming operation the average reaming thrust and torque were calculated from in-process measurements carried out using a Kistler piezoelectric dynamometer mounted under the workpiece holder. The average reaming thrust and reaming torque were derived from both recorded signals indicated in Fig. 2 as a time window span. The window span was defined as the time between two points placed on the stable part of the curve, considering half of the time the reamer interacted with the workpiece.

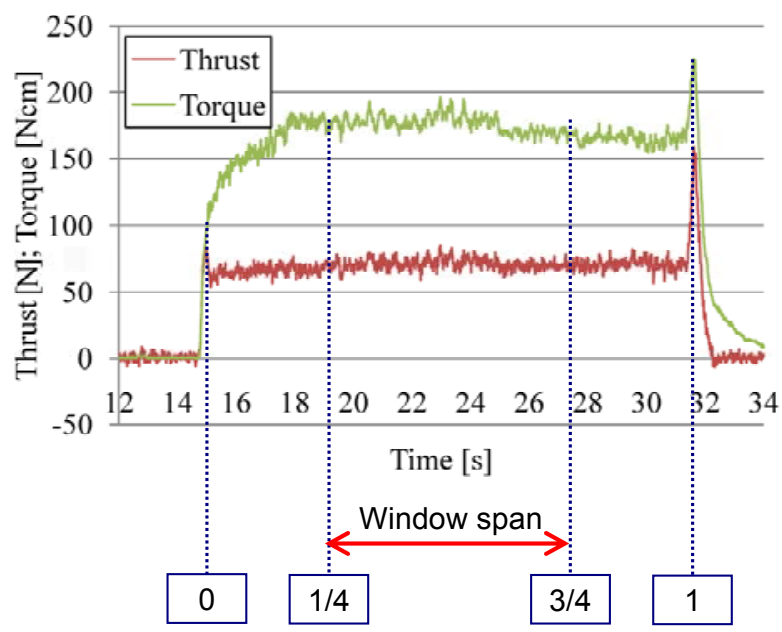

Fig. 2 - Typical reaming thrust and torque measurement, and definition of window span.

\subsection{Dimensional and geometrical measurements}

Reamed holes were measured using a tactile coordinate measuring machine (CMM, see Fig. 3). Both form parameters (roundness and cylindricity) and dimension (diameter) were measured. Specimens were measured at 4 levels, at 3,6, 9 and $12 \mathrm{~mm}$ from the bottom face of the workpiece; 8 points equally distributed were probed around the circumference at each level of the hole, giving a total of 32 points probed on each workpiece. Every measurement was repeated 5 times. For each measured circle, roundness was calculated, then, based on the 4-level measuring strategy, diameter of the hole and its form error (cylindricity) were calculated. All three measurands (diameter, cylindricity and roundness) were calculated based on the minimum zone method, according to ISO $1101[18]$.

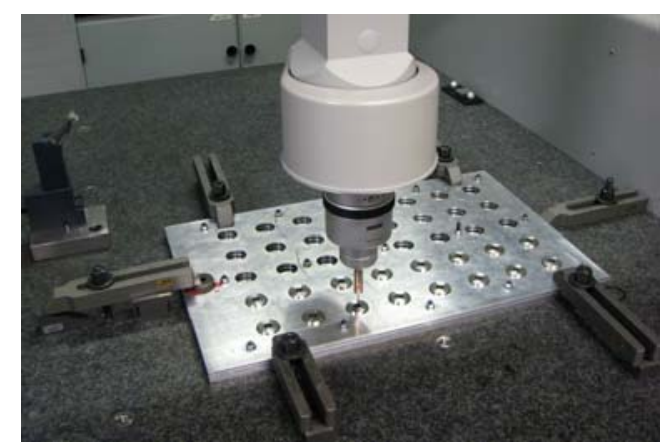

Fig. 3 - CMM measurement of reamed holes.

\subsection{Surface topography measurements}

The surface topography of the reamed holes was characterized in terms of average surface roughness $\mathrm{Ra}$ defined in ISO 4287 [19]. As discussed in [6], the Ra parameter is not appropriate to compare two different reamed surfaces; however, in this investigation, where the focus is on process repeatability, $\mathrm{Ra}$ was considered to be a convenient parameter, as discussed in section 6.2. Measurements were carried out using a skid stylus roughness tester equipped with a $2 \mu \mathrm{m}$ radius tip according to ISO 3274 [20]. Measuring profiles were recorded at 4 different positions equally distributed on the surface of the hole, both near the top (position A) and the bottom (position B). Each profile measurement was repeated 3 times, for a total of 24 profiles for each reamed hole. An evaluation length $\mathrm{In}=$ $4 \mathrm{~mm}$, low-pass $\lambda \mathrm{s}=2.5 \mu \mathrm{m}$ and high-pass $\lambda \mathrm{c}=0.8$ $\mathrm{mm}$ profile filtering, according to ISO 3274 [20], were applied.

\section{EXPERIMENTAL PLAN}

Different reaming conditions were investigated. Five process parameters were varied and their influence on the evaluation parameters (hole diameter, roundness, cylindricity, surface roughness, reaming torque and thrust) was evaluated. Each experimental production batch was composed of 15 specimens. All 15 reamed 
workpieces were measured. The experimental plan is shown in Table 5 where differences between experiments are highlighted with colours. Varied process parameters were: reamer diameter (i.e. depth of cut), cutting speed, feed (i.e. feed rate), type of feed (return of the tool after machining completion), MQL application.

\begin{tabular}{|l|c|c|c|c|c|c|c|c|}
\hline \multirow{2}{*}{ Parameter } & \multirow{2}{*}{ Symbol } & \multirow{2}{*}{ Unit } & \multicolumn{7}{|c|}{ Reaming operation } \\
\cline { 4 - 9 } & & & $\mathrm{R} 1$ & $\mathrm{R} 2$ & $\mathrm{R} 3$ & $\mathrm{R} 4$ & $\mathrm{R} 5$ & $\mathrm{R} 6$ \\
\hline Reamer diameter & $\mathrm{D}_{\mathrm{R}}$ & $\mathrm{mm}$ & 10.1 & 10.1 & 10.1 & 10.0 & 10.1 & 10.1 \\
\hline Depth of cut & $\mathrm{a} p$ & $\mathrm{~mm}$ & 0.10 & 0.10 & 0.10 & 0.05 & 0.10 & 0.10 \\
\hline Cutting speed & $V_{\mathrm{C}}$ & $\mathrm{m} / \mathrm{min}$ & 5 & 5 & 5 & 5 & 5 & 6 \\
\hline Revolutions & $\mathrm{N}$ & $\mathrm{rev} / \mathrm{min}$ & 158 & 158 & 158 & 159 & 158 & 189 \\
\hline Feed & $f$ & $\mathrm{~mm} / \mathrm{rev}$ & 0.315 & 0.315 & 0.21 & 0.21 & 0.21 & 0.21 \\
\hline Feed rate & $V_{f}$ & $\mathrm{~mm} / \mathrm{min}$ & 49.7 & 49.7 & 33.1 & 33.4 & 33.1 & 39.7 \\
\hline Reverse feed rate & - & - & slow & rapid & rapid & rapid & rapid & rapid \\
\hline Cutting time & $t$ & $\mathrm{sec}$ & 18.1 & 18.1 & 27.2 & 26.9 & 27.2 & 22.7 \\
\hline Oil temperature & $T$ & ${ }^{\circ} \mathrm{C}$ & $26 \pm 0.5$ & $28 \pm 0.5$ & $28 \pm 0.5$ & $25 \pm 0.5$ & $28.5 \pm 0.5$ & $28 \pm 0.5$ \\
\hline Oil pressure & $p$ & $\mathrm{bar}$ & 6 & 6 & 6 & 6 & 6 & 6 \\
\hline Oil flow rate & $\mathrm{Q}$ & $\mathrm{m} / \mathrm{h}$ & 50 & 60 & $55-60$ & 50 & $55-60$ & $55-60$ \\
\hline Nozzle positioning & - & - & $\mathrm{TB}$ & $\mathrm{TB}$ & $\mathrm{TB}$ & $\mathrm{TB}$ & $\mathrm{TT}$ & $\mathrm{TB}$ \\
\hline
\end{tabular}

Table 5 - Experimental plan of reaming tests.

\section{MEASURING UNCERTAINTY ASSESSMENT}

The uncertainty of measurements carried out to investigate the capability of the reaming process was determined for all measurands. In the following, the uncertainty assessment procedure is presented.

\subsection{Uncertainty of dimensional and geometrical measurements}

Uncertainty assessment of the measurements carried out with the CMM was performed following the procedure described in ISO 15530-3 [21]. This standard introduces a method for uncertainty assessment consisting on carrying out repeated measurements on a calibrated workpiece, with the same measuring conditions as those used for the actual measurands. The experimental method for uncertainty assessment is based on the substitution of the actual component with a calibrated workpiece (reference artefact). As reference artefact, a calibrated ring with nominal dimensions similar to the reamed holes was chosen. Expanded calibration uncertainties of the reference ring were as follows:

- Diameter $U_{\text {cal }}(D)= \pm 0.0010 \mathrm{~mm}$

- Roundness $U_{\text {cal }}(R)= \pm 0.0013 \mathrm{~mm}$

- Cylindricity $\mathrm{U}_{\text {cal }}(\mathrm{C})= \pm 0.0016 \mathrm{~mm}$

The uncertainty of measurements on reamed holes $\left(U_{\text {ream }}\right)$ was calculated as follows:

$$
U_{\text {ream }}(j)=k \cdot \sqrt{u_{c a l}^{2}+u_{p}^{2}+u_{w}^{2}}+|b|
$$

Where:

- $\quad U_{\text {ream }}=$ expanded combined uncertainty of measurements on reamed holes;

- $(j)=(D, R, C)$ depending on the measurand: diameter, roundness, cylindricity respectively;

- $\quad k=$ coverage factor $(=2)$ for a confidence level of approximately $95 \%$;

- $u_{\text {cal }}=$ standard calibration uncertainty of the reference ring;
- $u_{p}=$ standard uncertainty of the measurement procedure, calculated as standard deviation of repeated measurements on the ring taking into account the effect of variation of the measuring strategy (see Fig. 4).

- $u_{w}=$ temperature-related standard uncertainty, calculated for a maximum temperature variation of $\pm 1^{\circ} \mathrm{C}$; measurements were carried out in a controlled environment at standard temperature of $20 \pm 0.5^{\circ} \mathrm{C}$.

- $b=$ systematic error, calculated as a difference between the values reported in the ring calibration certificate and measured values by the CMM on the calibrated ring for all the measurand (D, R, C).

Finally the measuring uncertainty of the reamed holes was calculated using Eq. (1) and results are reported on Table 6].
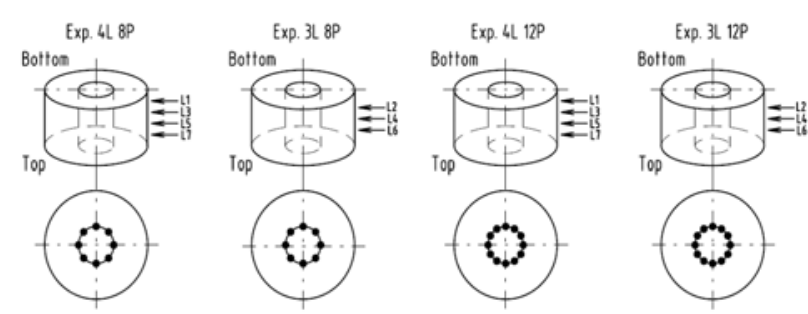

Fig. 4 - Measuring strategies for standard uncertainty $u_{p}$ assessment.

\begin{tabular}{|c|c|c|c|c|}
\hline \multirow{2}{*}{$\begin{array}{l}\text { Uncertainty } \\
\text { component }\end{array}$} & \multirow{2}{*}{ Symbol } & \multicolumn{3}{|c|}{ Standard uncertainty } \\
\cline { 3 - 5 } & & $\mathrm{D}$ & $\mathrm{R}$ & $\mathrm{C}$ \\
\hline Calibration & $u_{c a l}$ & 0.00049 & 0.00065 & 0.00080 \\
\hline Procedure & $u_{p}$ & 0.00043 & 0.00044 & 0.00130 \\
\hline Temperature & $u_{w}$ & $1.6 \mathrm{E}-04$ & $3.0 \mathrm{E}-08$ & $7.7 \mathrm{E}-08$ \\
\hline Systematic error & $b$ & 0.00117 & 0.00043 & 0.00056 \\
\hline $\begin{array}{c}\text { Expanded } \\
\text { combined } \\
\text { uncertainty }\end{array}$ & $\boldsymbol{U}_{\text {ream }}$ & $\mathbf{0 . 0 0 2 5}$ & $\mathbf{0 . 0 0 2 0}$ & $\mathbf{0 . 0 0 3 6}$ \\
\hline
\end{tabular}

Table 6 - Uncertainty budget for dimensional and geometrical CMM measurements of reamed holes.

\subsection{Uncertainty of roughness measurements}

An uncertainty assessment for the stylus roughness tester measurements was carried out taking into account both instrument calibration and variability of the machined surface. Therefore, the instrument was first calibrated using an ISO type C2 standard [22]. The instrument uncertainty for average roughness ( $\mathrm{Ra}$ ) measurements was calculated as follows:

$$
U_{\text {inst }}(R a)=k \cdot \sqrt{u_{c a l}^{2}+u_{r e p}^{2}+u_{b}^{2}}
$$

Where:

- $U_{\text {inst }}=$ expanded combined uncertainty of the stylus instrument;

- $\quad k=$ coverage factor $(=2)$ for a confidence level of approximately $95 \%$;

- $u_{c a l}=$ standard calibration uncertainty of the roughness standard; 
- $\quad u_{\text {rep }}=$ repeatability of the instrument, calculated as standard deviation of the mean of repeated measurements performed on the roughness standard;

- $u_{b}=$ standard uncertainty due to the background noise of the instrument, calculated as standard deviation of repeated roughness measurements on a ideally perfect optical flat.

- The expanded uncertainty of the instrument was calculated and the results are reported on Table 7.

\begin{tabular}{|c|c|c|c|}
\hline \multicolumn{3}{|c|}{ Standard uncertainty components } & $\begin{array}{c}\text { Comb. exp. unc. } \\
{[\mu \mathrm{m}]}\end{array}$ \\
\hline$u_{\text {cal }}$ & $u_{\text {rep }}$ & $u_{b}$ & $\boldsymbol{U}_{\text {inst }}(\mathbf{R a})$ \\
\hline 0.006 & 0.001 & 0.004 & $\mathbf{0 . 0 1 5}$ \\
\hline
\end{tabular}

Table 7 - Uncertainty budget for the calibration of the stylus instrument.

An uncertainty budget for Ra measurements on the reamed holes was then calculated taking into account the repeatability of actual measurements on the specimen. Three repeated measurements on the same track at two different positions (top and bottom of the hole) were considered for the uncertainty assessment. The final uncertainty of roughness measurements on the reamed holes was calculated as follows:

$$
U_{\text {ream }}(R a)=k \cdot \sqrt{u_{\text {inst }}^{2}+u_{\text {rep } \text {,surf }}^{2}}
$$

Where:

- $U_{\text {ream }}(R a)=$ expanded combined uncertainty of single roughness measurements on the reamed surface;

- $\quad k=$ coverage factor $(=2)$ for a confidence level of approximately $95 \%$;

- $u_{\text {inst }}=$ instrument standard uncertainty $\left(u_{\text {inst }}=U_{\text {inst }} / \mathrm{k}\right)$;

- $u_{\text {rep,surf }}=$ repeatability of the measurement on the reamed surface, calculated as standard deviation of three repeated measurements in the same track.

\begin{tabular}{|c|c|c|}
\hline \multicolumn{2}{|c|}{ Standard uncertainty components } & $\begin{array}{c}\text { Comb. exp. } \\
\text { unc. }[\mu \mathrm{m}]\end{array}$ \\
\hline$u_{\text {inst }}$ & $u_{\text {rep,surf }}$ & $U_{\text {ream }}(R \mathbf{R a})$ \\
\hline 0.0075 & 0.011 & $\mathbf{0 . 0 2 2}$ \\
\hline
\end{tabular}

Table 8 - Uncertainty of Ra measurements on reamed holes.

\section{RESULTS}

\subsection{Dimensional and geometrical measurements}

The reliability of the process was verified by comparing the measured diameter of 15 specimens, for each of the processing conditions presented in Table 5, with a $\mathrm{H} 7$ tolerance specified for the reaming operation (corresponding to a range between 0 and $+18 \mu \mathrm{m}$, referred to the nominal value). In the comparison, the measuring uncertainty calculated in section 5.1 was included. The verification gave positive response for all machining configurations and all measured specimens.
Roundness as well as cylindricity were verified to be smaller than the specified tolerance, also taking into account the uncertainty (see Fig. 5).

The $\mathrm{H} 7$ tolerance was verified for all reaming conditions. It was observed in experiments R4 that, when using a smaller reamer, a larger diameter, if compared to the nominal dimension, was obtained (see Fig. 6). This could be due to the fact that a smaller depth of cut $(0.05$ $\mathrm{mm}$ instead of $0.10 \mathrm{~mm}$ ) implied a less effective cutting action with build-up edge formation so that the cutting edge would produce a larger hole. At the same time, higher material removal had a detrimental effect on the surface finish (see section 6.2).

Form errors (roundness and cylindricity) resulted all in the same range (i.e. compatible, if measuring uncertainty was considered), regardless the reaming conditions (see Fig. 7 and Fig. 8).

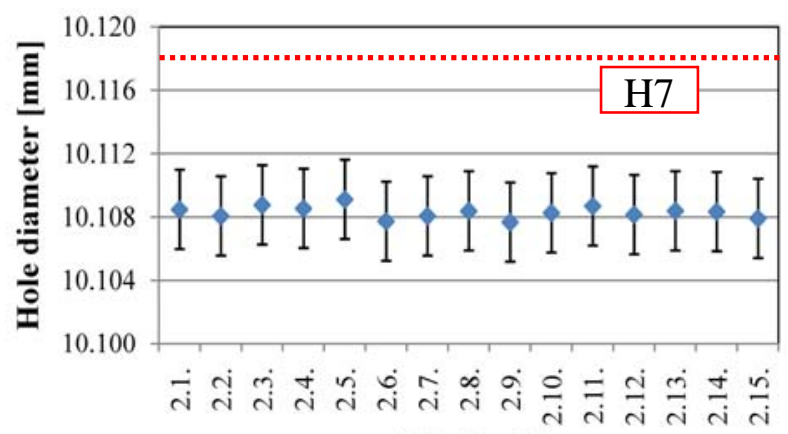

W.P. No. [-]
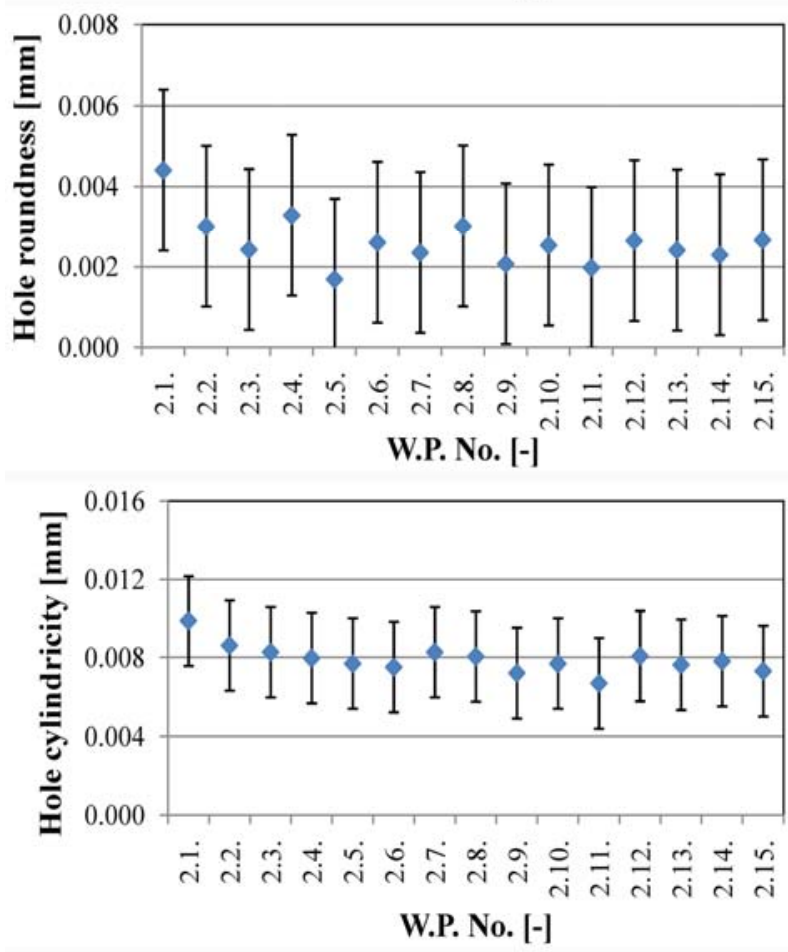

Fig. 5 - Example of tolerance verification for diameter, roundness and cylindricity of 15 reamed holes obtained during experiment R2 (error bars represent expanded uncertainty). 


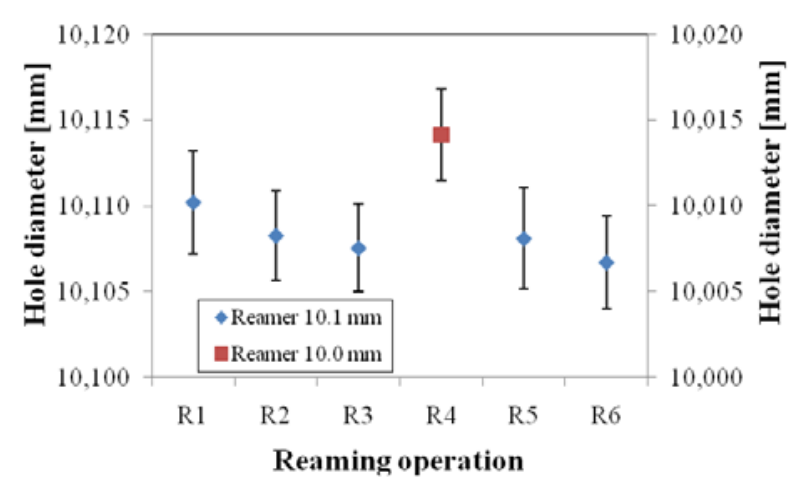

Fig. 6 - Diameter of reamed holes for different machining conditions.

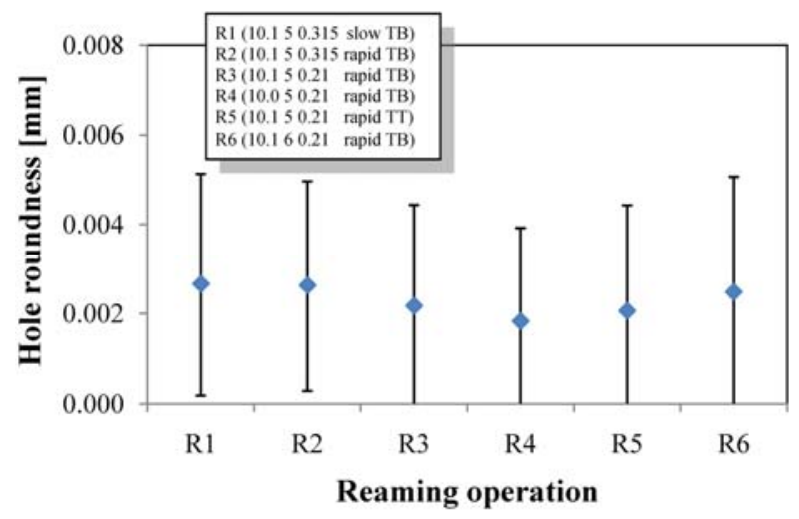

Fig. 7 - Roundness of reamed holes for different machining conditions.

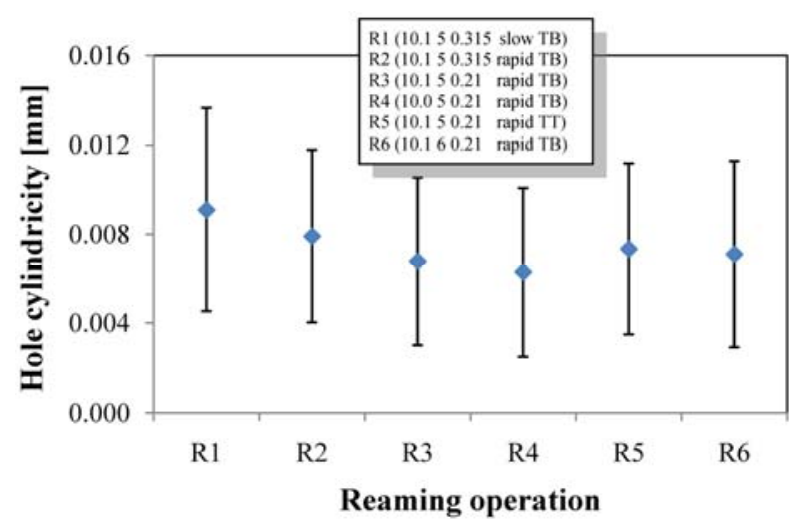

Fig. 8 - Cylindricity of reamed holes for different machining conditions.

As far as the process repeatability was concerned, all process configurations performed equivalently, being the standard deviation calculated over a batch of 15 specimens lower than $40 \%$ of the measuring uncertainty (see Table 9).

Finally, it is observed that the simple TT configuration for MQL application (R5) allowed good machining performance in terms of dimensional and geometrical accuracy. This solution is therefore recommendable to be used instead of the TB set-up, because of its easier implementation.

\begin{tabular}{|c|c|c|c|c|c|c|c|}
\hline \multirow{3}{*}{ Meas. } & \multirow{2}{*}{$\begin{array}{c}U_{\text {ream }}(\mathrm{j}) \\
{[\mu \mathrm{m}]}\end{array}$} & \multicolumn{6}{|c|}{ Reaming operation } \\
\cline { 3 - 8 } & & \multicolumn{6}{|c|}{ Process standard deviation $[\mu \mathrm{m}]$} \\
\cline { 3 - 8 } & 2.5 & 0.8 & 0.4 & 0.3 & 0.4 & 0.8 & 0.5 \\
\hline $\mathrm{D}$ & 2.0 & 0.8 & 0.6 & 0.6 & 0.4 & 0.7 & 0.8 \\
\hline $\mathrm{R}$ & $\mathrm{R} 2$ & $\mathrm{R} 3$ & $\mathrm{R}$ & $\mathrm{R}$ \\
\hline $\mathrm{C}$ & 3.6 & 1.4 & 0.7 & 0.6 & 0.6 & 0.7 & 1.1 \\
\hline
\end{tabular}

Table 9 - Process repeatability in terms of standard deviation of diameter (D), roundness (R), and cylindricity (C).

\subsection{Roughness measurements}

The surface quality of reamed holes is directly connected to the lubrication efficiency at the interface between cutting edge, chip and machined surface. It is of prime importance not only to obtain a surface with low roughness, but also a low roughness variation on different areas of the hole, as well as a high repeatability of surface topography on different specimens within the production batch. These three factors were therefore analyzed, as shown in Fig. 9, in terms of $\mathrm{Ra}$, which provides a rough approximation in the case of reamed surfaces.

Firstly, the absolute values of average surface roughness were compared considering the different reaming conditions. It could be observed that a smaller depth of cut (experiment R4) produced higher $\mathrm{Ra}$ values. Moreover, high $\mathrm{Ra}$ values were also obtained during experiment R6 where the cutting speed was increased from 5 to $6 \mathrm{~m} / \mathrm{min}$. On the other hand, when the TT set-up (experiment R5) for MQL application was used, the same surface roughness as for experiment R3 was obtained. Hence, it can be concluded that even with both nozzles from the top, an effective lubrication of the cutting area can be achieved and therefore a good surface finish can be obtained. So it is possible to take advantage of the easier set-up of the TT MQL application. Finally, a rapid reverse feed rate (see R1 vs. R2) is not producing a worse surface finish and it is therefore preferable in order to decrease machining time and enhance productivity. Low roughness values for the pilot hole in Fig. 9 derive from the fact that these holes were manufactured by grinding.

Secondly, the repeatability of the surface roughness was evaluated for specimens obtained in different reaming condition (see Table 10). In particular, it was observed that smaller depth-of-cut, TT application strategy and higher cutting speed lead to a less even surface of the hole, especially on the bottom position. As a consequence, a combined top-bottom lubrication system should be implemented, as well as an optimized cutting speed and depth-of-cut $(5 \mathrm{~m} / \mathrm{min}$ and $0.10 \mathrm{~mm}$ respectively).

Finally, process repeatability on a 15-specimen production batch was analyzed. The main conclusion is that high feed rate has lead to higher process repeatability in terms of $\mathrm{Ra}$. On the other hand, higher cutting speed leads to a less repeatable reaming process (see Table 10). 


\subsection{Torque and thrust measurements}

Reaming torque and thrust measurements were performed in order to calculate average values for each single experiment and then evaluate the repeatability for both parameters for the whole production.

A comparison in terms of average values of torque and thrust was performed (Fig. 10) showing that higher feed rate lead to higher values of these parameters, whereas a smaller depth-of-cut caused their decrease (due to the smaller chip section).

Low feed rate generally produced a higher repeatability, especially in terms of reaming thrust.

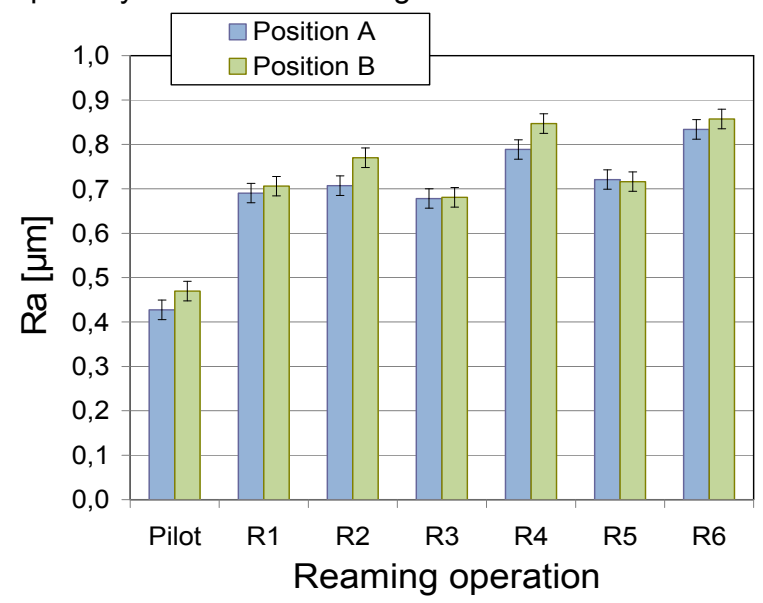

Fig. 9 - Surface roughness obtained using different reaming conditions Average values of 15

measurements, error bars represent $U_{\text {ream }}(R a)$ from

Table 8. "Pilot"' shows average value of roughness of holes before the reaming test.

\begin{tabular}{|c|c|c|c|}
\hline $\begin{array}{c}\text { Reaming } \\
\text { Operation }\end{array}$ & Position & $\begin{array}{c}\text { Average std. dev. } \\
\text { of 4 Ra } \\
\text { measurements } \\
\text { around the } \\
\text { circumference on } \\
\text { the same } \\
\text { specimen }\left(^{*}\right)[\mu \mathrm{m}]\end{array}$ & $\begin{array}{c}\text { Average std. } \\
\text { dev. of Ra } \\
\text { measurements } \\
\text { on 15 specimen } \\
\text { from the same } \\
\text { production } \\
\text { batch }\left(^{* *}\right)[\mu \mathrm{m}]\end{array}$ \\
\hline \multirow{2}{*}{ R1 } & A & 0.042 & 0.107 \\
\cline { 2 - 4 } & B & 0.057 & 0.073 \\
\hline \multirow{2}{*}{ R2 } & A & 0.048 & 0.097 \\
\cline { 2 - 4 } & B & 0.042 & 0.115 \\
\cline { 2 - 4 } & A & 0.035 & 0.148 \\
\hline \multirow{2}{*}{ R4 } & B & 0.045 & 0.126 \\
\cline { 2 - 4 } & B & 0.064 & 0.163 \\
\hline \multirow{2}{*}{ R5 } & A & 0.080 & 0.118 \\
\cline { 2 - 4 } R6 & B & 0.047 & 0.124 \\
\cline { 2 - 4 } & A & 0.070 & 0.120 \\
\hline
\end{tabular}

Table 10 - Process repeatability in terms of standard deviation of Ra within the same hole (*) and within a production batch $\left({ }^{* *}\right)$.

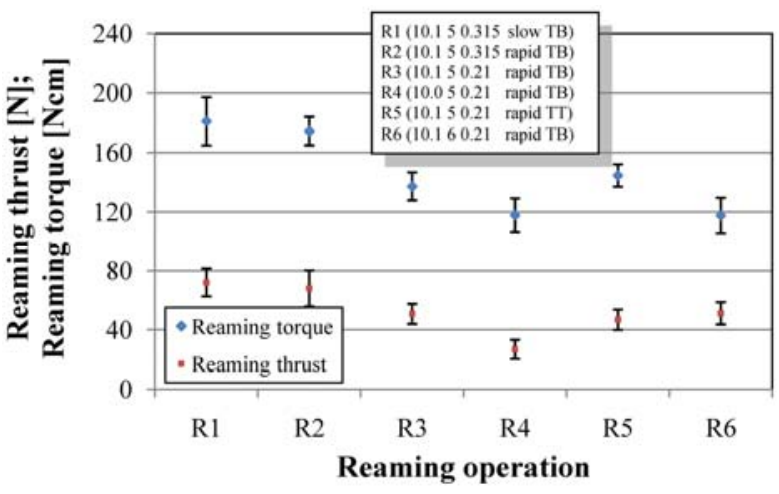

Fig. 10 - Reaming thrust and torque obtained using different reaming conditions (average values of 15 measurements, error bars represent standard deviation).

\section{CONCLUSION}

The capability of reaming when using minimal quantity lubrication (MQL) was investigated under different conditions. Austenitic stainless steel was selected as workpiece material for this research. Process performance in terms of hole characteristics as well as torque and thrust were analyzed using a metrological approach. It was observed that different cutting conditions determine different process performances. In particular, it was observed that a higher feed rate leads to lower and more repeatable roughness, but at the same time to higher and less repeatable reaming thrust and torque.

MQL in reaming leads to high quality results in terms of hole dimensions and surface finish. The tests have shown that MQL application using two nozzles from the top gives as good results as application with a nozzle from above and one from below.

\section{ACKNOWLEDGEMENTS}

The authors want to thank UNIMERCO A/S (Sunds, Denmark) for providing MQL equipment and tools.

\section{REFERENCES}

[1] Shaw, M.C (2005). Metal cutting principles, Oxford series on advanced manufacturing, Publ. Oxford University Press, New York (USA).

[2] Klocke, F. and Eisenblätter, G. (1997). Dry Cutting - Keynote Paper, Annals of CIRP, Vol.46/2, pp.519-526.

[3] Weinert, K., Inasaki, I., Sutherland, J.W. and Wakabayshi, T. (2004). Dry machining and Minimum Quantity Lubrication, Annals of CIRP, Vol.53/2, pp.511-537.

[4] Kalpakjian, S. and Schmid, S.R. (2008). Manufacturing Processes for Engineering Materials, 5th Ed., Publ. Prentice Hall, Singapore.

[5] De Chiffre, L. (1980) Mechanical testing and selection of cutting fluids. Lubrication Engineering, Vol.36, pp.33-39. 
[6] De Chiffre, L., Lassen, S., Pedersen, K.B. and Skade, S. (1994) A reaming test for cutting fluid evaluation, Journal of Synthetic Lubrication, Vol.11, pp.17-34.

[7] De Chiffre, L. and Belluco, W. (2000). Comparison of methods for cutting fluid performance testing, Annals of CIRP, Vol.49/1, pp.57-60.

[8] Belluco, W. (2000). Performance testing of cutting fluids, Technical University of Denmark, PhD Thesis.

[9] Belluco, W. and De Chiffre, L. (2001). Testing of vegetable-based cutting fluids by hole making operations, Lubrication Engineering, Vol.57, pp.1216.

[10] De Chiffre, L., Zeng, Z. and Belluco, W. (2001). An investigation of reaming test parameters used for cutting fluid evaluations. Lubrication Engineering, Vol.57, pp.24-28.

[11] Axinte, D., Belluco, W. and De Chiffre, L. (2001). Evaluation of cutting force uncertainty components in turning, Journal of Machine Tools and Manufacture, Vol.41, pp.719-730.

[12] Axinte, D., Belluco, W. and De Chiffre, L. (2001). Reliable tool life measurements in turning - An application to cutting fluid efficiency evaluation, Journal of Machine Tools and Manufacture, Vol.41, pp.1003-1014.

[13] Belluco, W. and De Chiffre, L. (2002). Surface integrity and part accuracy in reaming and tapping stainless steel with new vegetable based cutting oils, Tribology International, Vol.35, pp.865-870.

[14] De Chiffre, L. and Belluco, W. (2002). Investigation on cutting fluid performance using different machining operations. Lubrication Engineering, Vol.58, pp.22-29.

[15] Belluco, W. and De Chiffre, L. (2004). Performance evaluation of vegetable-based oils in drilling austenitic stainless steel, Journal of Materials Processing Technology, Vol.148, pp.171-176.

[16] De Chiffre, L., Andreasen, J.L., Lagerberg, S. and Thesken, I.-B. (2007). Performance Testing of Cryogenic $\mathrm{CO} 2$ as Cutting Fluid in Parting/Grooving and Threading Austenitic Stainless Steel, Annals of CIRP, Vol.53/1, pp.101104.

[17] Axinte, D. and De Chiffre, L. (2008). Effectiveness and resolution of tests for evaluating the performance of cutting fluids in machining aerospace alloys, Annals of CIRP, Vol.54/1, pp.129-132.

[18] ISO 1101:2004 Geometrical Product Specifications (GPS) -- Geometrical tolerancing -- Tolerances of form, orientation, location and run-out.

[19] ISO 4287:1997 Geometrical product specifications (GPS) -- Surface texture: Profile method - Terms, definitions and surface texture parameters.
[20] ISO 3274:1996 Geometrical Product Specifications (GPS) -- Surface texture: Profile method -- Nominal characteristics of contact (stylus) instruments.

[21] ISO/TS 15530-3:2004 Geometrical Product Specifications (GPS) -- Coordinate measuring machines (CMM): Technique for determining the uncertainty of measurement -- Part 3: Use of calibrated workpieces or standards.

[22] ISO 5436-1:2000 Geometrical Product Specifications (GPS) -- Surface texture: Profile method; Measurement standards -- Part 1: Material measures. 